\title{
Stimulus selection in children
}

\author{
JOHN A. ELLIS \\ Navy Personnel Research and Development Center, San Diego, California 92152
}

and

THOMAS J. THIEMAN

University of Mlinois, Urbana, Mlinois 61801

\begin{abstract}
Berlyne's (1960) hypothesis that complex stimuli increase arousal and focus attention was tested with verbally complex stimuli. Second grade students $(N=20)$ were presented with a list of paired associates with compound word/nonsense syllable stimuli and number responses. Half of the subjects were trained to a criterion of one correct anticipation of the list, and half were given eight overtraining trials. A transfer test was given in which the stimuli were split into the noun and nonsense components, and subjects were asked to recall the number paired with the compound of which the component was a member. The results of the transfer test were (1) subjects performed better on nonsense syllables than on words, and (2) overtraining did not improve performance. The preference for nonsense syllables supports Berlyne's position.
\end{abstract}

A number of child studies have supported Berlyne's (1960) hypothesis that complex stimuli increase arousal and focus attention. The majority of investigations have employed visually complex stimuli and have shown that children prefer visual complexity (e.g., Hicks \& Packwood, 1971). The present study attempts to extend Berlyne's hypothesis to verbal stimuli by examining children's preferences for verbal complexity. Verbal complexity can be defined in a number of ways (e.g., number of syllables). In this paper it will be defined in terms of association value (Archer, 1960). It is assumed that low association value items are more complex than high association value items because low value items are more difficult to encode (Prytulack, 1971).

A paired-associate task involving compound stimuli was used to investigate preferences for verbal complexity. A number of studies using this task have shown that subjects often select only one component of the compound stimulus in learning the association. The present experiment was designed so that the subject could select either a verbally complex stimulus component (nonsense syllable) or a verbally simple one (word) as the functional stimulus. Berlyne would predict that children will select the more complex stimulus, i.e., the nonsense syllable. A more intuitive prediction is that words will be selected, because they should be easier for children to encode than nonsense syllables (assuming the words are part of the child's vocabulary). The fact that adults given this task do select the words

This research was presented at the Midwestern Psychological Association Convention, Chicago, Illinuis, 1976. The work was accomplished while both authors were at the University of Illinois, Champaign. The opinions expressed are those of the authors and do not necessarily reflect those of the Navy Department. This paper is sponsored by William E. Montague, who takes full editorial responsibility for its contents.
(James \& Greeno, 1967) supports this prediction. In addition, Baumeister and Berry (1968), using the same task, found that older children (10-year-olds) selected colors over CVCs. (Colors are presumably less complex than CVCs.) However, Jensen and Rohwer (1965) observed that younger children are more likely to learn paired associates by rote than by generating mediators for encoding. Given this finding, Berlyne's position regarding the present experiment is not unreasonable. If young children do not employ mediation, they will not realize an advantage by selecting the words. Furthermore, if children perceive nonsense syllables as more complex than words, they should, according to Berlyne's hypothesis, select the nonsense syllable.

A second issue addressed in this study is whether overtraining will improve performance on the unselected component. James and Greeno (1967) found that overtrained adults learned about the unselected component. However, research by Siegal (1968) and Siegal and Corsini (1969) indicates that young children do not learn about incidental or peripheral cues unless they are specifically instructed to do so. In the present study, if subjects view the unselected component as incidental, there should be no overtraining effect.

\section{METHOD}

Twenty-five second graders were given a six-item pairedassociate list. The mean chronological age of the subjects was 8.0 years. Five subjects were eliminated because they failed to learn the list in 20 trials. The remaining subjects were randomly divided into two equal groups. The children were tested individually in a quiet office in a school building during normal class hours. Each child was shown examples of the type of paired associates used in the experiment and given standard pairedassociate instructions. The list of stimuli was then presented using the anticipation procedure, with eight random orderings of the items. The list was presented on a memory drum at a 
5:3-sec rate, with an 8 -sec intertrial interval. This presentation rate was adopted to maximize the opportunity for responding during the long test (stimulus only) interval, while reducing the chance for rehearsal with a shorter study (joint presentation) period. The subjects were told they could guess if they were not certain of the correct response.

The stimuli were word (three-letter nouns, mean association value 100$)$ and nonsense syllable (CVC, mean association value 51) compounds, and responses were single-digit numbers. The order of the words and nonsense syllables in the compounds was counterbalanced. Half $(10)$ of the subjects were trained to a criterion of one correct anticipation of the list and half (10) were given eight additional trials. Following list learning, a transfer test was given in which the stimuli were split into the noun and nonsense components. This resulted in a 12-item paired-associate transfer list in which half the stimuli were words and half were nonsense syllables. Subjects were asked to recall the number paired with the component's compound. The subjects were given four anticipation trials on the transfer list. The data were the number of words and nonsense syllables on which subjects made no errors over the four transfer trials (James \& Greeno, 1967).

\section{RESULTS AND DISCUSSION}

A 2 (criterion training vs. overtraining) by 2 (nonsense syllables vs. words) analysis of variance was performed on the number of stimuli components on which subjects made no errors over the four transfer trials. The only significant effect was for nonsense syllables vs. words, $F(1,18)=14.40, p<.01$. The mean number correct for each condition is criterion-nonsense $=3.4$, criterion-words $=2.1$, overtraining-nonsense $=3.7$, overtraining-words $=1.7$. No differences were observed between components which had appeared first and second during acquisition.

It is clear that significantly more digit responses were correctly recalled over all four transfer trials for the nonsense syllable components than for the words. This result extends Berlyne's hypothesis to verbal stimuli and indicates that learning strategies employed by children are different from those used by adults. In addition, the failure to observe an overtraining effect supports Siegel's (1968) finding that young children do not attend to incidental stimuli. This result is also indicative of learning strategy differences between young children and adults.

\section{REFERENCES}

ARCHER, E. J. A re-evaluation of the meaningfulness of all possible CVC trigrams. Psychological Monographs, 1960, 74(10, Whole No. 497).

Baumeister, A. A., \& BerRy, F. M. Context stimuli in verbal paired-associate learning by normal children and retardates. Psychological Record, 1968, 18, 185-190.

Berlyne, D. E. Conflict, arousal and curiosity. New York: McGraw-Hill, 1960.

Hicks, R. A., \& PACKwood, J. Effects of structural complexity in bigrams on paired-associate learning and retention in children. Journal of Educational Psychology, 1971, 62, 290-292.

James, C. T., \& Greeno, J. G. Stimulus selection at different stages of paired-associate learning. Journal of Experimental Psychology, 1967, 74, 75-83.

Jensen, A. R., \& Rohwer, W. J. Syntactical mediation of serial and paired-associate learning as a function of age. Child Development, 1965, 36, 601-608.

Prytulack, L. S. Natural language mediation. Cognitive Psychology, 1971, 2. 1-56.

Siegel, A. W. Variables affecting incidental learning in children. Child Development, 1968. 39, 957-968.

Siegel, A. W., \& Corsini, D. A. Attentional differences in children's incidental learning. Journal of Educational Psychology, 1969, 60, 65-70.

(Received for publication April 18, 1976.) 